\title{
La relatividad en la capacidad de elegir
}

\author{
Guillermo Ernesto García Picado ${ }^{1}$
}

1 Estudiante de II año de Contaduría Pública y Finanzas. UNAN-Managua/FAREM-Estelí. Email: darkguiller95@ gmail.com

¿Qué elementos condicionan mi vida? Muchas veces me he hecho este tipo de preguntas, y es en este escrito donde reflexiono en voz alta sobre mí mismo. Pretendo revisar mi vida como ha sido, como es y como quiero que sea. Cada día muchas personas nos podemos engañar si realmente elegimos lo que queremos hacer o lo que otras personas quisieran que hiciéramos. Muchas veces es muy diferente lo que yo pienso, de lo que piensan los demás de mí, y esta contradicción puede ser capaz de condicionarme, física, económica y psicológicamente. En este escrito, quiero profundizar e incitar a mi sub-consiente a comprender como estoy realmente y librarme de las visiones obsoletas a las que puedo estar atado.

Mi principal objetivo es mi proyección al futuro. Quiero reflexionar sobre lo que tengo y necesito para cumplir mis metas, que están ligadas a mi visión futura, y qué condiciones se pueden presentar para satisfacer mis necesidades. Considerando los antecedentes de la sociedad donde vivimos, las personas piensan más en lo material, y como grupo se imponen reglas que terminan imposibilitándolos mentalmente, por ejemplo cuando se cree que, si al ser jóvenes y no se posee nada, no se podemos ser capaz de mejorar.

Me pregunto: ¿Qué es capacidad? y ¿Que es libertad?, entiendo por capacidad los recursos y las acciones que tiene o ejerce cada individuo. Por libertad deduzco que es la capacidad del ser humano para elegir según su propia voluntad. De esta manera, la capacidad de elegir en libertad parte de los recursos con los que cuento para poder elegir a voluntad.

La palabra recursos no la tomare por el sentido material, la usare como recursos de conocimiento y más adelante tomaré en cuenta su sentido económico. Me pregunto: ¿Qué conocimientos adquiridos soy capaz de manejar para escoger lo que hago o quiero hacer por mi voluntad y consentimiento?. Siempre debo de pensar en adquirir nuevos conocimientos ya que sin estos no sabré lo que quiero, o lo que estoy eligiendo, y lo más importante es que no seré capaz de darme cuenta de lo que pasa a mi alrededor.

Considero que es importante crear una proyección de visión, es decir que debo de crear una perspectiva de quien soy actualmente y quien quiero ser en el futuro. Personalmente, y al igual que otras personas, tengo muchos sueños que anhelo cumplir. Estos sueños son mis principales metas, son el camino a seguir para 
avanzar. Cuando no se tiene metas, hay que crearlas, un corredor no termina una carrera sin tener una meta adonde llegar, o un salmón no sabe hacia dónde nadar sin un objetivo o razón. Me doy cuenta que en mi vida "estoy en el aire" a como expresa Rubén Darío en su poema "Lo fatal": "No sabemos ni a donde vamos ni de dónde venimos".

La proyección de visión me ayudara a aclarar mis ideas, porque estoy encerrado en un mundo creado por las demás personas. Mis padres y mis familiares son los principales responsables al escoger lo que es mejor para mí, sin concientizar lo que realmente a mí me gusta, o lo nuevo que quiero experimentar, y que yo no asumo por miedo a experimentar las cosas nuevas y a salir de mi espacio de comodidad que conozco.

Una visión futura es capaz de quitar los grilletes y ser libre de pensar por mí mismo, por desarrollar nuevas ideas en mi vida, y lo más importante es lo que espero de mí mismo. En mi mentalidad, lo primero debe ser mis deseos como persona, y pensar en un futuro mejor, es aquí donde proyecto mi visión de un yo en años futuros.

Si algo debo de limitar son a las personas que nos encierran, que no me estimulan a mejorar, que solo intentan que este igual a ellos. Aunque no quiero alejarme de estas personas, más bien deseo que estén a mi lado, y es ahí donde debo de diferenciar entre quienes me limitan y quienes me están ayudando a luchar por lo que tanto deseo.

Es importante profundizar sobre los recursos que tengo para cumplir con mis sueños. Los recursos personales y materiales, que están a mí alrededor y los que poseo, son condiciones importantes. En el caso de que no posea las condiciones económicas que necesito para cumplir con mis metas, de seguro tendré que crearme oportunidades para mejorarlas. Un ejemplo claro es que hoy tengo 18 años y vivo con mis padres, quiero estudiar en la mejor universidad, pero ninguno de ellos tiene las condiciones económicas para darme la educación que deseo, pero yo tengo otras oportunidades como mejorar mis calificaciones y conseguir una beca. Aunque esto debí de pensarlo años atrás para estar prevenido, en caso de que mi primer plan con mis padres no se diera.

Las condiciones con las que puedo contar no siempre son materiales. La sociedad no siempre es considerada con las personas de bajos recursos, pero esto no significa que no se presenten oportunidades donde demostraré de lo que soy capaz, ya que no existe límite en mis posibilidades, porque yo soy el primero que debo de creer en mí mismo, ¿Quién soy para que los demás crean en mí?

Las personas a mi alrededor muchas veces me condicionan de que no podré cumplir lo que me propongo, pero solo debo de pensar que la diversión esta en demostrar de la madera que estoy hecho. Muchos jóvenes hoy en día trabajan y estudian desde temprana edad, así que no debo de tener pena de lo que los demás piensan. Mi condición económica mejorara, dependiendo de lo que haga. Hoy en día es normal esforzarse y aprender sin importad la edad, así que no será raro que conozca personas de mayor edad que estudien conmigo.

¿Qué es lo que considero indispensable en el transcurso de mi vida? La sociedad reconoce como indispensable todo lo material, y siempre será el factor principal para mejorar nuestras vidas, es lo primero que verán los demás para juzgarme y también es lo mismo que yo les responderé cuando me pregunten sobre lo que necesito para cumplir mis metas. 
Las personas que consideran que sus necesidades son mayores que sus soluciones se ciegan ante la adversidad. Me he propuesto tratar de hacer la diferencia, me propongo implementar otro tipo de soluciones que no se les hayan ocurrido a los demás o a quienes hayan enfrentado un problema similar. He aquí la importancia de observar lo que está a mí alrededor y es donde tomo ejemplos que considero para mi beneficio.

La sociedad me ha enseñado que las condiciones sociales no son estáticas y que se puede cambiar de condición económica, para ello debo de mejorar mi educación, porque esto me llevará a mejorar mi economía porque obtendré un mejor título ante la sociedad.

Para concluir considero que el principal elemento que condiciona la libertad de elegir, se refiere a no poseer una visión positiva de uno mismo como persona. Ahí es cuando aparece mi reflexión sobre lo que tengo económicamente y los conocimientos previos aprendidos, compararlos con los conocimientos actuales y lo que quiero en mi futuro. Luego pensar en lo que necesito para cumplir mi visión futura, y resolver las condiciones adversas que surgirán en el transcurso de mi vida. Así identificare mi capacidad de elegir a voluntad, de crear mi propia vida y asumir las soluciones apropiadas a los problemas que se me presenten, además de escoger que quiero hacer, con quienes quiero estar y como quiero mi vida 